\title{
MORTALITY PATTERN OF HOSPITALIZED CHILDREN IN A REFERRAL HOSPITAL FROM UPPER ASSAM, NORTH EAST INDIA: A RECORD BASED RETROSPECTIVE ANALYSIS
}

\author{
Rita Panyang Kataki1 ${ }^{1}$ Arpita Gogoi², Chandra Jyoti Bora ${ }^{3}$, Pritikar Dowerah4, Manjit Baruah ${ }^{5}$ \\ ${ }^{1}$ Assistant Professor, Department of Paediatrics, Assam Medical College and Hospital. \\ ${ }^{2}$ Assistant Professor, Department of Paediatrics, Assam Medical College and Hospital. \\ ${ }^{3}$ Assistant Professor, Department of Paediatrics, Assam Medical College and Hospital. \\ 4 Professor, Department of Paediatrics, Assam Medical College and Hospital. \\ ${ }^{5}$ Registrar of PSM, Assam Medical College and Hospital.
}

ABSTRACT

\section{OBJECTIVE}

Mortality rate of children is one of the important indicator of health status of country. India is one of the major contributor of under 5 mortality of the world. The present study was aimed at finding the causes of mortality among children admitted in pae diatric ward of Assam Medical College Hospital during last two years and provides epidemiological information related to mortality.

\section{MATERIALS AND METHODS}

A retrospective cross-sectional descriptive study over 2 years' period from 1st July 2013 to $31^{\text {st }}$ June 2015 using data retrieved from the Hospital's Admission and Death Record Register. Data collected was entered into a spreadsheet using SPSS software package version 16.0 .

\section{RESULTS}

A total of 10970 children comprising of 4873 (44.4\%) males and 6097 (55.5\%) of females were admitted to the Paediatric Department during this 24 months' period. A total number of children died during this period was 814 comprising of 474 (58.2\%) males and 334 (41\%) females. Overall mortality among males and females were $9.72 \%$ and $5.47 \%$ respectively.

An overall mortality of $7.42 \%$ was noted in cases admitted to the Paediatric ward. Out of total 814 paediatric deaths, 460 (57.9\%) were infant and more than 1/3rd (35.8\%) of infants died in new-born period; 186 (23.4\%) died in age group 1-5 years and 148 $(18.1 \%)$ died in age group $>5$ years. Majority of neonatal mortality was due to birth asphyxia (33.1\%) followed by septicaemia (31.4\%) and prematurity, LBW (18.5\%). The common cause of post neonatal death was septicaemia (24\%) and respiratory tract infection (24\%) followed by meningitis (22.4\%). Septicaemia (17.8\%) was the leading cause of death among infant. Acute encephalitis syndrome is the most common cause of death in 1-5 yrs. (24.1\%) and $>5$ yrs. (25\%) age group.

\section{CONCLUSION}

The pattern of childhood mortality has been documented in the present study. The results from this study confirm that high neonatal deaths were mainly due to birth asphyxia, while after neonatal period mortality due to pneumonia and acute encephalitis syndrome and septicaemia. This needs urgent upgradation of facilities in the tertiary care hospitals for prevention of deaths and strengthening vaccination for vaccine-preventable disease.

\section{KEYWORDS}

Child Mortality; Pattern; Cause of Death; Birth Asphyxia; Acute Encephalitis.

HOW TO CITE THIS ARTICLE: Kataki RP, Gogoi A, Bora CJ, et al. Mortality pattern of hospitalized children in a referral hospital from Upper Assam, North East India: a record based retrospective analysis. J. Evolution Med. Dent. Sci. 2016;5(31):1622-1625,

\section{INTRODUCTION}

Childhood mortality is very important indicator of health status of a country. The causes of mortality are often poorly documented in developing countries. The Medical Records Department in a teaching hospital has a system of compilation and retention of records, yet the acquisition of meaningful statistics from these records for health care planning and review is lacking.

Financial or Other, Competing Interest: None.

Submission 23-02-2016, Peer Review 21-03-2016,

Acceptance 28-03-2016, Published 16-04-2016.

Corresponding Author:

Dr. Rita Panyang Kataki,

Department of Paediatrics,

Assam Medical College,

Dibrugarh-786002,

Assam.

E-mail: panyang.rita.dr@gmail.com

DOI: $10.14260 /$ jemds $/ 2016 / 382$
Mortality data from hospitalized patients reflect the causes of major illnesses and care seeking behaviour of the community as well as the standard of care being provided. ${ }^{1}$ Records of vital events like death constitute an important component of the Health Information System. Hospital-based death records provide information regarding the causes of deaths, case fatality rates, age and sex distribution, which are of great importance in planning health care services. A better understanding of childhood mortality could contribute to a more effective approach to saving these lives. A country needs sound epidemiological information to prioritize, plan and implement public health programmes. There is a paucity of information about direct causes of child mortality in developing countries. ${ }^{1}$ This information also provides the basis for patient care and helps the administration in managing day-to-day hospital affairs.

The present study was aimed at finding the causes of mortality among children admitted in Paediatric ward of a 
tertiary level hospital during a two-year period and provides epidemiological information related to mortality.

\section{MATERIALS AND METHODS}

Assam Medical College and Hospital is one of the oldest medical college of India and located in Dibrugarh, Assam, North Eastern part of India. This study was carried out at Department of Paediatrics Assam Medical College and Hospital. This Hospital has a 90 bedded paediatric ward and 20 bedded NICU (inborn). Children below the age of 12 years with illness requiring hospitalization are admitted to the Paediatric Department, both from the outpatient and emergency departments.

A records based retrospective study was done covering a period of 2 years from July 1, 2013 to June 31, 2015. Data for the study was retrieved from the Hospital's admission and death record register. A paediatrician is available for consultation round - the clock in the ward under the guidance of senior consultants. The diagnosis and cause of death were largely clinically based with supportive laboratory results. Records of children from birth to 12 years, who died in the hospital were reviewed. Data extracted from the records included age, sex, principal diagnosis/cause of death and time of death. Post-mortem examination was not done for the patients because of lack of manpower for this service.

Data collected was entered into a spreadsheet using SPSS software package version 16.0. Descriptive statistics was used to analyse the obtained data. Missing data and the patients from a Neonatal Intensive Care Unit (Inborn) and Paediatric Surgical Unit were excluded from the study.

\section{RESULTS}

A total of 10970 children comprising of 4873 (44.4\%) males and 6097 (55.5\%) of females were admitted to the Paediatric Department from July 2013 to June 2015. During this 24 months' period, 814 children died with an overall mortality of $7.42 \%$.

Overall mortality among admitted males and females were $9.72 \%$ and $5.47 \%$ respectively (Table 1). Male:female ratio in age group $<1 \mathrm{month}, 1 \mathrm{~m}$ to $<1 \mathrm{yr}$., $1-5 \mathrm{yrs}$. and $>5 \mathrm{yrs}$. were 1.4:1, 1.6:1, 1.3:1, 1.1:1 respectively (Table 2).

Out of total 814 paediatric deaths, $460(57.9 \%)$ were infants and $1 / 3^{\text {rd }}(35.8 \%)$ of infants died in the new-born period; 186 (23.4\%) died in age group 1-5 years and 148 $(18.1 \%)$ died in age group $>5$ years.

Majority of neonatal mortality was due to birth asphyxia (33.1\%) followed by septicaemia (31.4\%) and prematurity, LBW (18.3\%) (Table 3). The common cause of infant death was septicaemia (24\%) and respiratory tract infection (24\%) followed by meningitis (22.3\%), congenital heart disease (6.1\%) and acute encephalitis syndrome (5.1\%) (Table 4). Septicaemia (26.9\%) was the leading cause of death among infants.

Acute encephalitis syndrome is the most common cause of death in 1-5 yrs. (24.2\%) and $>5$ yrs. (25\%). Other important cause of mortality in the age group of 1-5 yrs. was meningitis $(7.5 \%)$, respiratory tract infection $(7 \%)$, anaemia $(7 \%)$ and severe acute malnutrition (6.5\%). In age group $>5$ yrs., other important causes of mortality were tuberculosis (9.5\%), hepatic failure (8.1\%), septicaemia $(7.4 \%)$, anaemia (6.8\%) and poisoning (5.4\%) (Table 5)
Noteworthy points observed in the present study was that there were only 3 diarrhoea deaths reported in $<5$ yrs. age group; death in the new-born period was less than post neonatal period; dead due to birth asphyxia was commonest in new-born period.

\begin{tabular}{|c|c|c|c|c|}
\hline & Total Admission & & \multicolumn{2}{|c|}{ Total Deaths } \\
\hline & No. & \% & No. & \% \\
\hline Male & 4873 & 44.4 & 474 & 9.72 \\
\hline Female & 6097 & 55.5 & 334 & 5.47 \\
\hline & 10970 & & 814 & 7.42 \\
\hline \multicolumn{3}{|c|}{ Table 1: Sex Distribution of Cases } \\
\hline
\end{tabular}

\begin{tabular}{|c|c|c|c|c|c|}
\hline \multirow{2}{*}{ Age } & \multicolumn{4}{|c|}{ Sex } & Total \\
\cline { 2 - 6 } & \multicolumn{2}{|c|}{ Male } & \multicolumn{2}{c|}{ Female } & \\
\hline & No. & $\mathbf{\%}$ & No. & $\mathbf{\%}$ & \\
\hline Below 1 month & 98 & 59.4 & 67 & 40.6 & 165 \\
\hline 1 m - 1 year & 185 & 62.7 & 110 & 37.3 & 295 \\
\hline 1 to 5 years & 106 & 57.0 & 80 & 43.0 & 186 \\
\hline Above 5 years & 78 & 52.7 & 70 & 47.3 & 148 \\
\hline Total & $\mathbf{4 6 7}$ & $\mathbf{5 8 . 8}$ & $\mathbf{3 2 7}$ & $\mathbf{4 1 . 2}$ & $\mathbf{7 9 4}$ \\
\hline
\end{tabular}

\begin{tabular}{|c|c|c|}
\hline & Frequency & Percent \\
\hline Birth Asphyxia & 56 & 33.1 \\
\hline Septicaemia & 53 & 31.4 \\
\hline Preterm & 31 & 18.3 \\
\hline $\mathrm{N} / \mathrm{A}^{*}$ & 11 & 6.5 \\
\hline Congenital Malformation & 7 & 4.1 \\
\hline Meningitis & 3 & 1.8 \\
\hline Miscellaneous & 3 & 1.8 \\
\hline Bilirubin Encephalopathy & 2 & 1.2 \\
\hline Surgical & 2 & 1.2 \\
\hline Congenital Heart Disease & 1 & 0.6 \\
\hline Total & 169 & 100 \\
\hline \multicolumn{3}{|c|}{ Table 3: Causes of Neonatal Death } \\
\hline
\end{tabular}

\begin{tabular}{|c|c|c|}
\hline & Frequency & Percent \\
\hline RTI & 71 & 24.1 \\
\hline Septicaemia & 71 & 24.1 \\
\hline Meningitis & 66 & 22.4 \\
\hline N/A & 22 & 7.5 \\
\hline Congenital Heart Disease & 18 & 6.1 \\
\hline Acute Encephalitis Syndrome & 15 & 5.1 \\
\hline Tuberculosis & 6 & 2.0 \\
\hline Miscellaneous & 5 & 1.7 \\
\hline Severe Acute Malnutrition & 4 & 1.4 \\
\hline Disseminated Intravascular & 3 & 1.0 \\
\hline Coagulopathy & 3 & 1.0 \\
\hline Hepatic Encephalopathy & 2 & 0.7 \\
\hline Congenital Malformation & 2 & 0.7 \\
\hline Preterm & 3 & 1.0 \\
\hline Renal & 2 & 0.7 \\
\hline Surgical & 1 & 0.3 \\
\hline Acquired Heart disease & 1 & 0.3 \\
\hline Seizure Disorder & $\mathbf{2 9 5}$ & $\mathbf{1 0 0}$ \\
\hline \multicolumn{2}{|c|}{ Total } & \\
\hline Table 4: Causes of Post Neonatal Death
\end{tabular}




\begin{tabular}{|c|c|c|c|c|c|}
\hline & \multicolumn{2}{|c|}{$\begin{array}{l}\text { to } 5 \\
\text { years }\end{array}$} & \multicolumn{2}{|c|}{$\begin{array}{c}\text { Above } 5 \\
\text { years }\end{array}$} & \multirow{2}{*}{ Total } \\
\hline & No. & $\%$ & No. & $\%$ & \\
\hline $\mathrm{N} / \mathrm{A}^{*}$ & 16 & 8.6 & 10 & 6.8 & 26 \\
\hline $\begin{array}{l}\text { Acute Encephalitis } \\
\text { Syndrome }\end{array}$ & 45 & 24.2 & 37 & $\begin{array}{c}25 . \\
0\end{array}$ & 82 \\
\hline Acute Gastroenteritis & 3 & 1.6 & 0 & 0.0 & 3 \\
\hline $\begin{array}{l}\text { Acquired Heart } \\
\text { Disease }\end{array}$ & 7 & 3.8 & 5 & 3.4 & 12 \\
\hline $\begin{array}{c}\text { Congenital Heart } \\
\text { Disease }\end{array}$ & 2 & 1.1 & 3 & 2.0 & 5 \\
\hline $\begin{array}{l}\text { Disseminated } \\
\text { Intravascular } \\
\text { Coagulopathy }\end{array}$ & 1 & 0.5 & 2 & 1.4 & 3 \\
\hline Miscellaneous & 5 & 2.7 & 9 & 6.1 & 14 \\
\hline $\begin{array}{l}\text { Respiratory Tract } \\
\text { Infection }\end{array}$ & 13 & 7.0 & 2 & 1.4 & 15 \\
\hline $\begin{array}{l}\text { Severe Acute } \\
\text { Malnutrition }\end{array}$ & 12 & 6.5 & 7 & 4.7 & 19 \\
\hline Anaemia & 13 & 7.0 & 10 & 6.8 & 23 \\
\hline $\begin{array}{c}\text { Hepatic } \\
\text { Encephalopathy }\end{array}$ & 5 & 2.7 & 12 & 8.1 & 17 \\
\hline Malaria & 1 & 0.5 & 0 & 0.0 & 1 \\
\hline Malignancy & 5 & 2.7 & 5 & 3.4 & 10 \\
\hline Meningitis & 14 & 7.5 & 3 & 2.0 & 17 \\
\hline Seizure Disorder & 12 & 6.5 & 3 & 2.0 & 15 \\
\hline Poisoning & 2 & 1.1 & 8 & 5.4 & 10 \\
\hline Renal & 2 & 1.1 & 4 & 2.7 & 6 \\
\hline Septicaemia & 11 & 5.9 & 11 & 7.4 & 22 \\
\hline Surgical & 7 & 3.8 & 3 & 2.0 & 10 \\
\hline \multirow[t]{2}{*}{ Tuberculosis } & 10 & 5.4 & 14 & 9.5 & 24 \\
\hline & 186 & & 148 & & 334 \\
\hline $\begin{aligned} 5: D i \\
1-\end{aligned}$ & II & 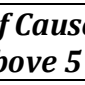 & $f D e$ & & \\
\hline
\end{tabular}

*N/A - (Not Available) missing data excluded from analysis.

\section{DISCUSSION}

Despite substantial progress on maternal and child mortality, neither MDG 4 nor MDG 5 targets will be met. The global Under-Five Mortality Rate (U5MR) fell by 53\% between 1990 and 2015, short of the targeted two-thirds reduction. ${ }^{2}$ It is estimated that 5.9 million children under five will die in 2015. Nearly 16,000 children die every day and $83 \%$ of deaths in children under age five are caused by infectious, neonatal or nutritional conditions. ${ }^{2}$ The African Region and South East Asia Region account for a disproportionate share of maternal, new-born and child deaths. About half of under-five deaths occur in only five countries: China, Democratic Republic of the Congo, India, Nigeria and Pakistan. India (21\%) and Nigeria $(13 \%)$ together account for more than a third of all under-five deaths. ${ }^{3}$

In the present study, paediatric deaths (814) in relation to total paediatric admissions (10970) in two-year period showed overall mortality of paediatric patients in present study was $7.42 \%$, which was higher than that observed in the Patil SW et al. ${ }^{4}(4.57 \%)$ study done at tertiary care hospital Latur. Higher mortality in the present study may be due to the large number of admissions in critical conditions, late referring of patient and unavailability of PICU in the hospital. But these statistics was lower than the Roy R et al. study. ${ }^{5}$ (9.87\%) conducted in 2008 Kolkata and Godale L et al. ${ }^{6}$ (9.8\%) conducted in 2013 at Western Maharashtra and Charles NC et al. (11\%) 2014 studied at Nigeria. ${ }^{7}$

The number of admissions was more in female (6097) than male (4873), but Roy R et al. ${ }^{5}$ and Singhi S et al. ${ }^{8}$ studies reported greater male admission rate in hospitals than female children. This high female admission rate in the present study may be due to lack of sex discrimination in this part of country. Though the risk of death in paediatric age group is highest during neonatal period and in various studies. 4,5 they found neonatal death was more than post neonatal period. But in the present study, death in post-neonatal period (33.2\%) is more than the neonatal period $(22.3 \%)$. This may be due to exclusion of new-born from inborn NICU and better antenatal care and new-born care by implementation of various programmes by NHM. Death of post-neonatal period was highest in present study, may be due to late referral in critical condition and unavailability of PICU.

Current study shows that deaths in paediatric age group were more in males $(58.7 \%)$ than the females $(41.3 \%)$. This shows biological vulnerability of males to infection is more than females, as they are biologically stronger in their early ages. Patil SW et al. ${ }^{4}$ reported the same statistics in their study. The male preponderance has also been documented in various studies. $4,6,8$

In the present study, commonest cause of death $<1 \mathrm{yr}$. is septicaemia and in above 1 yr. was acute encephalitis syndrome. Similar records were observed by Roy R et al. 5 in their study in Kolkata 2008 and Naik JD. 9 in Western Maharashtra 2014.

The risk of death in children is closely related to the environment they live in, care seeking behaviour of the parents, proper treatment opportunity they received and care after birth and antenatal care. The risk is highest during neonatal period, because they are very vulnerable to infection. In present study highest cause of death in new-born period is due to birth asphyxia followed by neonatal sepsis. Charles NC et al. report similar result in their study conducted in Nigeria $2014 .^{7}$

\section{CONCLUSION}

The pattern of mortality in different paediatric age group found in the present study showed that the trend of death in neonate has changed from septicaemia, prematurity to birth asphyxia. This suggests that we are in need of more comprehensive antenatal and early intervention to prevent birth asphyxia and proper treatment of new-born sepsis.

The death in the infant $\left(1 \mathrm{~m}-1 \mathrm{yr}\right.$.) is more than $1 / 3^{\text {rd }}$ of total childhood mortality recorded. Acute Encephalitis Syndrome is the highest cause of mortality above 1 year. So there is an urgent need for upgradation of facilities in the tertiary care hospitals for prevention of deaths and strengthening of JE vaccination in the community. There is also a need to strengthen Information, Education and Communication (IEC) activities, so that the health services given are fully utilized.

\section{REFERENCES}

1. Park K. Principles of epidemiology and epidemiologic methods. In Park K (ed): Park's textbook of preventive and social medicine. Banarsidas Bhanhot, Jabalpur India 2013;22 ${ }^{\text {nd }}$ Ed:50-77.

2. WHO Report. Health in 2015: from MDGS to SDGS , Dec 2015;1-12. 
3. WHO: UNICEF, World Bank, UN DESA, UNPD. Level and trends in child mortality. Report 2015, Estimates Developed by the UN Inter-agency group for child.

Mortality estimation. Available on http//www.childmortality.org/files_V11/download/lev els and trends in child mortality report 2015.pdf

4. Patil SW, Godale LB. Mortality pattern of hospitalized children in a tertiary care hospital in latur: a record based retrospective analysis. Natl J Community Med 2013;4(1):96-9.

5. Roy R, Nandy S, Shrivastava P, et al. Mortality pattern of hospitalized children in a tertiary care hospital of Kolkata. Indian J Community Med 2008;33(3):187-9.
6. Godale L, Mulage S. Trend and pattern of paediatric deaths in tertiary care hospital solapur, Maharashtra. Indian J MCH 2012;14:2-10.

7. Charles NC, Chuku A, Anazodo NM. Childhood mortality in federal medical centre umuahia, south eastern nigeria. Oman Med J 2014;29(5):320-4.

8. Singhi S, Gupta G, Jain V. Comparison of pediatric emergency patients in a tertiary care hospital vs. A community hospital. Indian Pediatr 2004;41:67-72.

9. Naik JD, Dolare JR, Jatti GM, et al. Mortalty pattern among hospitalised children in a tertiary care hospital of western maharashtra. International Journal of General Medicine and Pharmacy (IJGMP) 2014;3(6):7-12. 